\title{
COMPOSIÇÃO FLORÍSTICA DE UM FRAGMENTO DE FLORESTA ESTACIONAL SEMIDECÍDUA NO MUNICÍPIO DE SÃO CARLOS-SP ${ }^{1}$
}

\author{
Luciana Álvares da Silva² e João Juares Soares ${ }^{3}$
}

\begin{abstract}
RESUMO - O presente trabalho teve por objetivo o levantamento florístico de um fragmento de floresta estacional semidecídua com aproximadamente 112 ha, localizado no município de São Carlos-SP, entre 21 ${ }^{\circ} 55^{\prime}$ e $22^{\circ} 00^{\prime}$ sul e $47^{\circ} 48^{\prime}$ e $47^{\circ} 52^{\prime}$ oeste. A precipitação média anual é de $1.440 \mathrm{~mm}$. As temperaturas médias mensais variam de $15,63{ }^{\circ} \mathrm{C}$ (das mínimas) a $26,82^{\circ} \mathrm{C}$ (das máximas) no ano. No levantamento florístico foram encontradas 146 espécies, pertencentes a 44 famílias e 96 gêneros, devendo ser ressaltado que 12 taxa foram identificados em nível de gênero e nove plantas não foram identificadas. O índice de diversidade de Shannon-Wiener foi de 3,45 nats/ind. A comparação com outras formações florestais semelhantes no Estado de São Paulo, pelo índice de similaridade de Sorensen, mostrou-se baixa.
\end{abstract}

Palavras-chave: Levantamento florístico, fragmento florestal e floresta semidecídua.

\section{FLORISTIC COMPOSITION OF A MESOPHYLLOUS SEMIDECIDUOUS FOREST FRAGMENT, IN SÃO CARLOS-SP}

\begin{abstract}
This study aimed to carry out a floristic survey of a semideciduous forest. The area is a secondary forest, located in São Carlos, SP, coordinates $21^{\circ} 55^{\prime} S$ and $47^{\circ} 48^{\prime \prime} W$. The annual average rain precipitation is $1,440 \mathrm{~mm}$. The annual average temperature varies from $15.63{ }^{\circ} \mathrm{C}$ to $26.82^{\circ} \mathrm{C}$. In the floristic survey 146 species were identified, distributed within 44 families and 96 genera. The Shannon-Wiener diversity index ( $\left.H^{\prime}\right)$ was 3.45 nats/ind. There was little similarity with other forest fragments of similar vegetation in the state of São Paulo, by the Sörensen Index.
\end{abstract}

Key words: $\quad$ Floristic survey, forest fragment and semideciduous forest.

\section{INTRODUÇÃO}

O Estado de São Paulo apresenta três grandes formações vegetais: as florestas úmidas de encosta, na província do planalto atlântico e na província costeira; os cerrados, no oeste-noroeste da província do planalto ocidental; e, entre essas duas formações, a depressão periférica, coberta em sua maior parte por uma formação florestal mais seca que a atlântica e menos xeromorfa que o cerrado, denominada de "floresta estacional semidecídua" ou "floresta mesófila" (Catharino, 1989).

Os ecossistemas florestais, que no início de seu processo de desenvolvimento cobriam mais de $80 \%$ da superfície de São Paulo, foram drasticamente reduzidos a menos de 5\% da área do Estado (Consema, 1985).

Com a expansão da cafeicultura, da cana-de-açúcar, da citricultura e do reflorestamento, principalmente na

1 Recebido para publicação em 29.1.2002.

Aceito para publicação em 9.9.2003.

Parte da tese de doutorado do primeiro autor.

2 Doutora PPG-ERN - Universidade Federal de São Carlos - UFSCar, <luciana.alvares@ zipmail.com.br>; ${ }^{3}$ Prof. Colaborador do Departamento de Botânica - UFSCar e Visitante da UEM, <juares@ power.ufscar.br>. 
região de São Carlos-SP, área do presente estudo, as florestas estacionais semidecíduas foram reduzidas, restando pequenos fragmentos na forma de capoeiras ou como pequenas áreas residuais (Kronka et al., 1998). Hoje, as florestas residuais do interior paulista são representadas apenas por fragmentos espaçadamente distribuídos pelo Estado. As pequenas extensões de florestas estacionais semidecíduas correspondem aos parques e reservas e a matas residuais em propriedades privadas, que devido às facilidades de acesso e às pressões agropecuárias e imobiliárias sofrem desmatamento acelerado (KotchetkoffHenriques \& Joly, 1994).

A conservação das florestas estacionais semidecíduas depende, fundamentalmente, da conservação dos fragmentos florestais dispersos pelo Estado (Tabanez et al., 1997). As análises florísticas e estruturais permitem obter informações sobre a situação dos fragmentos, para que possam ser estabelecidas estratégias de conservação.

O objetivo deste trabalho foi realizar o levantamento florístico de um fragmento de floresta estacional semidecídua no interior do Estado de São Paulo.

\section{MATERIAL E MÉTODOS}

\section{1. Área de Estudo}

A Reserva de Floresta Estacional Semidecídua, fazenda Canchim, de propriedade da EMBRAPA PECUÁRIA SUDESTE - CPPSE, localiza-se no município de São Carlos, Estado de São Paulo, entre 21 ${ }^{\circ} 55^{\prime}$ e $22^{\circ} 00^{\prime}$ sul e $47^{\circ} 48^{\prime}$ e $47^{\circ} 52^{\prime}$ oeste. O fragmento estudado fica ao lado da sede da fazenda e encontra-se a aproximadamente $8 \mathrm{~km}$ do perímetro urbano do município de São Carlos, localizado na parte central do Estado.

O fragmento apresenta uma área de aproximadamente 112 ha de floresta estacional semidecídua, segundo a classificação do IBGE (1993). Apresenta um dossel que varia de 7 a 25 m, não sendo possível distinguir uma nítida estratificação. É comum a ocorrência de lianas no seu interior, que em vários trechos do fragmento chegam a dificultar o acesso ao interior da mata. Em um levantamento feito por Hora (1999), no mesmo fragmento estudado, foram encontradas 109 espécies de lianas. O autor acredita que tais lianas têm grande relação com o histórico de perturbação do fragmento (perturbação antrópica e dinâmica natural). Pode-se observar também a ocorrência de clareiras abertas pela queda de árvores.

R. Árvore, Viçosa-MG, v.27, n.5, p.647-656, 2003
A reserva é mantida sem exploração desde 1934, porém no passado ocorreu o corte seletivo, principalmente de jequitibás e perobas. Há mais ou menos 10 anos ocorreu um incêndio na área, que foi controlado rapidamente, não chegando a causar grandes danos (Comunicações pessoais - Embrapa Pecuária Sudeste - CPPSE).

O clima da região de São Carlos, segundo a classificação de Köppen, é uma transição entre os tipos $\mathrm{Cwa}_{\mathrm{i}}$ $A w_{i}$, entre um clima quente de inverno seco, que localmente vai de abril a setembro, e um tropical com verão úmido e inverno seco (Tolentino, 1967). A precipitação média anual é de $1.440 \mathrm{~mm}$, predominando nos meses mais quentes. A temperatura média compensada anual é de $26,82^{\circ} \mathrm{C}$ e a média das mínimas, $15,63^{\circ} \mathrm{C}$. A umidade relativa média anual do ar é de 75,6\%.

A reserva apresenta topografia plana, levemente ondulada e altitude média de $850 \mathrm{~m}$. Segundo Oliveira \& Prado (1984), o relevo da região do Planalto de São Carlos é suave-ondulado, com declives de 3 a $5 \%$. A unidade de solo predominante é a do Latossolo Vermelho Distrófico típico, com estreita faixa no interior da mata de Latossolo Vermelho Distroférrico e a presença de Latossolo Vermelho-Amarelo Distrófico na região mais periférica da reserva (Calderano Filho et al., 1998).

\subsection{Metodologia}

Para o levantamento florístico, a área foi percorrida periodicamente durante um ano (julho/1997 a julho/1998) e foram feitas observações ocasionais nos dois anos sucessivos, quando foram coletadas todas as espécies arbóreo-arbustivas que apresentavam materiais férteis. As exsicatas foram incorporadas ao herbário do Departamento de Botânica da Universidade Federal de São Carlos, onde foram devidamente catalogadas (Silva, 2001). O material herborizado foi identificado (Lorenzi, 1992; Lorenzi, 1998 e Martius, 1967) por comparação em herbários, ou remetido para especialistas.

A diversidade florística foi estimada pelo índice de diversidade de Shannon-Wiener (H') (Mueller-Dombois \& Ellenberg, 1974). Para a comparação florística, foi utilizado o índice de similaridade de Sörensen (Brower \& Zar, 1984).

\section{RESULTADOS E DISCUSSÃO}

Foram encontradas 146 espécies, pertencentes a 44 famílias e 96 gêneros, sendo 12 taxa identificados 
somente em gênero e nove plantas sem identificação (Quadro 1).

As famílias com maiores números de espécies foram Euphorbiaceae $(9,03 \%)$, Rubiaceae $(6,45 \%)$, Leguminosae Papilionoideae $(5,81 \%)$, Lauraceae $(4,52 \%)$, Melastomataceae $(4,52 \%)$, Meliaceae $(4,52 \%)$, Myrtaceae (4,52\%), Rutaceae (4,52\%), Leguminosae Mimosoideae $(3,87 \%)$, Annonaceae $(3,87 \%)$ e Solanaceae $(3,87 \%)$, perfazendo um total de $55,50 \%$ das espécies amostradas. Nos levantamentos florísticos realizados em florestas estacionais semidecíduas no Estado de São Paulo, por Martins (1979), Matthes (1980),
Cavassan et al. (1984), Pagano \& Leitão Filho (1987) e Cesar (1988), também é marcante a presença dessas famílias, o que leva a deduzir que existe uma similaridade com essas áreas.

As famílias Anacardiaceae, Arecaceae, Bombacaceae, Burseraceae, Caricaceae, Connaraceae, Erythroxylaceae, Lecythidaceae, Loganiaceae, Malpighiaceae, Myristicaceae, Nyctaginaceae, Proteaceae, Sapotaceae e Violaceae apresentaram-se apenas com uma única espécie cada, e estas 15 famílias representaram 33,33\% do total de famílias e $9,68 \%$ das espécies encontradas no levantamento florístico.

Quadro 1 - Lista das famílias e espécies ocorrentes no levantamento florístico da Reserva de Floresta Estacional Semidecídua, da fazenda Canchim, São Carlos-SP. (Num. UFSCar = número da coleta do herbário da UFSCar)

Table 1 - Floristic composition of a mesophyllous semideciduous forest fragment of Canchim Farm, São Carlos-SP, Brazil

\begin{tabular}{|c|c|c|}
\hline Família/Espécie & Nome Popular & Num. UFSCar \\
\hline \multicolumn{3}{|l|}{ ANACARDIACEAE } \\
\hline Astronium graveolens Jacq. & Guaritá, gonçalo-alves & 4630 \\
\hline \multicolumn{3}{|l|}{ ANNONACEAE } \\
\hline Annona cacans Warm. & Cortição, araticum-cagão & 4637 \\
\hline Duguetia lanceolata A. St.-Hil. & Araticum, pindaíba & 4650 \\
\hline Guatteria nigrescens Mart. & Pindaíba-preta & 4655 \\
\hline Rollinia silvatica (A. St.-Hil.) Mart. & Araticum-do-mato, cortiça & 4656 \\
\hline Xylopia brasiliensis Spreng. & Pau-de-mastro, pindaíba & 4660 \\
\hline Xylopia sp. & & - \\
\hline \multicolumn{3}{|l|}{ APOCYNACEAE } \\
\hline Aspidosperma parvifolium A.DC. & & 4698 \\
\hline Aspidosperma polyneuron Müll. Arg. & Peroba-rosa & 4696 \\
\hline Aspidosperma ramiflorum Müll. Arg. & Guatambu, guatambu-amarelo & 4697 \\
\hline Forsteronia minutiflora Müll. Arg. & & 4706 \\
\hline \multicolumn{3}{|l|}{ ARECACEAE } \\
\hline Euterpe edulis Mart. & Juçara, palmito-juçara & - \\
\hline \multicolumn{3}{|l|}{ ASTERACEAE } \\
\hline Piptocarpha axillaris (Less.) Baker & Vassoura-preta, vassourão & 4719 \\
\hline Vernonia diffusa Less. & Pau-toucinho & 4722 \\
\hline \multicolumn{3}{|l|}{ BIGNONIACEAE } \\
\hline Jacaranda micrantha Cham. & Caroba, carobão & 4740 \\
\hline Zeyheria tuberculosa Bureau ex Verl. & Bolsa-de-pastor, ipê-tabaco & 4757 \\
\hline \multicolumn{3}{|l|}{ BOMBACACEAE } \\
\hline Ceiba speciosa (A.St. -Hil.) Gibbs \& Semir & Paineira & 4758 \\
\hline \multicolumn{3}{|l|}{ BORAGINACEAE } \\
\hline Cordia discolor Cham. & & 4761 \\
\hline Cordia sericicalyx A.DC. & Poleiro-de-morcego & - \\
\hline
\end{tabular}


Quadro 1, cont.

Table 1, cont.

\begin{tabular}{|c|c|c|}
\hline Família/Espécie & Nome Popular & Num. UFSCar \\
\hline \multicolumn{3}{|l|}{ BURSERACEAE } \\
\hline Protium heptaphyllum (Aubl.) March. & Almecegueira & 4762 \\
\hline \multicolumn{3}{|l|}{ CARICACEAE } \\
\hline Jacaratia spinosa (Aubl.)A.DC. & Jacaratiá, mamãozinho & 4816 \\
\hline \multicolumn{3}{|l|}{ CECROPIACEAE } \\
\hline Cecropia glaziovi Snethl. & Embaúba & - \\
\hline Cecropia pachystachya Trécul & Embaúba & 4837 \\
\hline \multicolumn{3}{|l|}{ CELASTRACEAE } \\
\hline Maytenus ilicifolia Mart. & Espinheira-santa & 4826 \\
\hline Maytenus robusta Reissek & Cafezinho-do-mato & 4823 \\
\hline \multicolumn{3}{|l|}{ COMBRETACEAE } \\
\hline Terminalia argentea Mart. & Capitão-do-campo & 3413 \\
\hline Terminalia brasiliensis (Cambess.) Eichl.' & Capitão-do-mato, amarelinho & - \\
\hline \multicolumn{3}{|l|}{ CONNARACEAE } \\
\hline Connarus regnellii Schellenb. & Árvore-dos-feiticeiros & 4829 \\
\hline \multicolumn{3}{|l|}{ ERYTHROXYLACEAE } \\
\hline Erythroxylum ambiguum Peyr. & Mercúrio-do-campo & 4850 \\
\hline \multicolumn{3}{|l|}{ EUPHORBIACEAE } \\
\hline Actinostemon communis (Müll.Arg.) Pax & Laranjeira-brava & 4854 \\
\hline Actinostemon concolor (Spreng.) Müll.Arg. & Pau-rainha & 4859 \\
\hline Alchornea glandulosa Poepp. \& Endl. & Maria-mole & - \\
\hline Aparisthimium cordatum (Juss.) Baill. & Tapiá-branco & - \\
\hline Croton floribundus Spreng. & Capixingui & 4875 \\
\hline Croton piptocalyx Müll.Arg. & Caixeta, caixeta-mole & - \\
\hline Croton priscus Croizat & Pau-sangue & - - \\
\hline Croton urucurana Baill.' & Sangra-d'água & 4879 \\
\hline Croton cf. warmingii Müll. Arg. & & 4876 \\
\hline Maprounea guianensis Aubl. & Bonifácio & 4901 \\
\hline Micrandra elata Müll.Arg. & Leiteiro & 4880 \\
\hline Pachystroma longifolium (Nees) I. M. Johnst. & Canxim & 4885 \\
\hline Sapium glandulatum (Vell.) Pax & Pau-de-leite & 4892 \\
\hline Savia dictyocarpa Müll.Arg. & Guaraiuva & 4887 \\
\hline \multicolumn{3}{|l|}{ FLACOURTIACEAE } \\
\hline Casearia gossypiosperma Briq. & Cambroé, pau-de-espeto & - \\
\hline Casearia sylvestris $\mathrm{Sw}$. & Guaçatonga, café-do-diabo & 1132 \\
\hline \multicolumn{3}{|l|}{ LAURACEAE } \\
\hline Endlicheria paniculata (Spreng.) J.F.Macb. & Canela-do-brejo & 5031 \\
\hline Nectandra megapotamica (Spreng.) Mez & Canelinha & 5033 \\
\hline Nectandra sp. & & - \\
\hline Ocotea corymbosa Mez & Canela-fedida, canela-preta & 5034 \\
\hline Ocotea martiana Mez & & 5035 \\
\hline Ocotea odorifera (Vell.) Rohwer & Canela-sassafrás & - \\
\hline Ocotea sp. & & - \\
\hline \multicolumn{3}{|l|}{ LECYTHIDACEAE } \\
\hline Cariniana estrellensis Kuntze & Jequitibá-branco & - \\
\hline
\end{tabular}

Continued.

R. Árvore, Viçosa-MG, v.27, n.5, p.647-656, 2003 
Quadro 1, cont.

Table 1, cont.

\begin{tabular}{|c|c|c|}
\hline Família/Espécie & Nome Popular & Num. UFSCar \\
\hline \multicolumn{3}{|l|}{ LEGUMINOSAE CAESALPINIOIDEAE } \\
\hline Senna macranthera (DC. ex Collad.) Irwin \& Barneby & Fedegoso & - \\
\hline Holocalyx balansae Micheli & Alecrim-de-campinas & 4814 \\
\hline Hymenaea courbaril L. & Jatobá & 571 \\
\hline \multicolumn{3}{|l|}{ LEGUMINOSAE MIMOSOIDEAE } \\
\hline Anadenanthera colubrina (Vell.) Brenan & Angico-branco & 1668 \\
\hline Anadenanthera macrocarpa (Benth.) Brenan & Angico-vermelho & - \\
\hline Enterolobium contortisiliquum (Vell.) Morong & Orelha-de-negro & - \\
\hline Inga marginata Willd. & Ingá-mirim & 4150 \\
\hline Inga striata Benth. & Ingá-banana & 3392 \\
\hline Piptadenia gonoacantha (Mart.) J.F. Macb. & Pau-jacaré & - \\
\hline \multicolumn{3}{|l|}{ LEGUMINOSAE PAPILIONOIDEAE } \\
\hline Centrolobium tomentosum Guill. ex Benth. & Araribá & 4990 \\
\hline Cyclolobium vecchi A.Samp. ex Hoelne & Louveira & - \\
\hline Lonchocarpus guilleminianus (Tul.) Malme & Rabo-de-macaco, embira-de-sapo & 5003 \\
\hline Lonchocarpus sp. & & - \\
\hline Machaerium aculeatum Raddi & Jacarandá-de-espinho & 5004 \\
\hline Machaerium nyctitans (Vell.) Benth. & Bico-de-pato, jacarandá-espinho & 5007 \\
\hline Machaerium stipitatum (DC.) Vogel & Pau-de-malho, feijão-cru & 5012 \\
\hline Myroxylon peruiferum L.f. & Bálsamo, óleo-de-cabreúva & 5008 \\
\hline Platypodium elegans Vogel & Faveiro, jacarandá-do-campo & 1088 \\
\hline \multicolumn{3}{|l|}{ LOGANIACEAE } \\
\hline Strychnos brasiliensis (Spreng.) Mart. & Salta-martinho & 1236 \\
\hline \multicolumn{3}{|l|}{ MALPIGHIACEAE } \\
\hline Byrsonima sp. & & - \\
\hline \multicolumn{3}{|l|}{ MELASTOMATACEAE } \\
\hline Leandra atropurpurea Cogn. & & - \\
\hline Leandra glazioviana Cogn. & & - \\
\hline Leandra scabra DC. & Camará-do-mato & - \\
\hline Miconia albicans Triana & Folha-branca & 4066 \\
\hline Miconia brunnea DC. & Cabuçu & - \\
\hline Miconia elegans Cogn. & & - \\
\hline Miconia latecrenata (DC.) Naudin & Quaresmão & - \\
\hline \multicolumn{3}{|l|}{ MELIACEAE } \\
\hline Cabralea canjerana (Vell.) Mart. & Canjerana & - \\
\hline Cedrela fissilis Vell. & Cedro & - \\
\hline Guarea kunthiana A. Juss. & Cura-madre & - \\
\hline Guarea macrophylla Vahl & Marinheiro & - \\
\hline Trichilia catigua A. Juss. & Catiguá & - \\
\hline Trichilia elegans A. Juss. & Catiguá-de-folha-miúda & - \\
\hline Trichilia hirta L. & Carrapeta & - \\
\hline \multicolumn{3}{|l|}{ MYRISTICACEAE } \\
\hline Virola bicuhyba (Schott) Warb. & Bicuíba, bicuíba-vermelha & 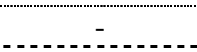 \\
\hline
\end{tabular}

Continua...

Continued... 
Quadro 1, cont.

Table 1, cont.

\begin{tabular}{|c|c|c|}
\hline Família/Espécie & Nome Popular & Num. UFSCar \\
\hline \multicolumn{3}{|l|}{ MONIMIACEAE } \\
\hline Mollinedia longifolia Tul. & & - \\
\hline Siparuna guianensis Aubl. & Limão-bravo & 4176 \\
\hline \multicolumn{3}{|l|}{ MORACEAE } \\
\hline Ficus enormis (Mart. ex Miq.) Miq. & Figueira & - \\
\hline Ficus guaranitica Chodat & Figueira-branca & - \\
\hline Maclura tinctoria D. Don ex Steud. & Tajuba & - \\
\hline \multicolumn{3}{|l|}{ MYRSINACEAE } \\
\hline Cybianthus densiflorus Miq. & & - \\
\hline Myrsine lancifolia Mart. & Canelinha & 1778 \\
\hline \multicolumn{3}{|l|}{ MYRTACEAE } \\
\hline Eugenia cf. blastantha (O.Berg) D. Legrand & Grumixama-miúda & - \\
\hline Eugenia moraviana O.Berg & Cambuim & - \\
\hline Eugenia umbelliflora O. Berg. & Guamirim & - \\
\hline Eugenia sp.1. & & - \\
\hline Eugenia sp.2. & & - \\
\hline Myrcia formosiana DC. & & - \\
\hline Myrciaria tenella (DC.) O. Berg & Cambuí & 4557 \\
\hline \multicolumn{3}{|l|}{ NYCTAGINACEAE } \\
\hline Guapira opposita (Vell.) Reitz & Maria mole & 3409 \\
\hline \multicolumn{3}{|l|}{ PIPERACEAE } \\
\hline Piper aduncum L.' & Erva-de-jaboti & - \\
\hline Piper amalago L. & Falso-jaborandi & 4305 \\
\hline Piper arboreum Aubl. & Pimenta-de-macaco & - \\
\hline \multicolumn{3}{|l|}{ Piper sp. } \\
\hline \multicolumn{3}{|l|}{ PROTEACEAE } \\
\hline Roupala brasiliensis Klotzsch & Carne-de-vaca & 4373 \\
\hline \multicolumn{3}{|l|}{ RHAMNACEAE } \\
\hline Colubrina glandulosa Perkins & Saraguagi-vermelho & - \\
\hline Rhamnidium elaeocarpum Reissek' & Saraguagi-amarelo & - \\
\hline \multicolumn{3}{|l|}{ RUBIACEAE } \\
\hline Faramaea multiflora A.Rich.' & Café-do-mato & - \\
\hline Chomelia obtusa Cham \& Schltdl. & & - \\
\hline Ixora warmingii Müll.Arg. & Araribe & - \\
\hline Ixora venulosa Benth. & & - \\
\hline Ixora sp. & & - \\
\hline Palicourea croceoides Ham.' & & - \\
\hline Palicourea marcgravii A.St.-Hil.' & Erva-de-rato-verdadeira & 4408 \\
\hline $\begin{array}{l}\text { Psychotria sessilis (Vell.) Müll.Arg. var. hancorniifolia (Benth.) } \\
\text { Steyerm. }\end{array}$ & Matadeira & - \\
\hline \multicolumn{3}{|l|}{ Psychotria sp. } \\
\hline \multicolumn{3}{|l|}{ RUTACEAE } \\
\hline Balfourodendron riedelianum Engl. & Pau-marfim & - \\
\hline Esenbeckia febrifuga A. Juss. & Laranjeira-do-mato & $\begin{array}{c}2714 \\
\text { Continu } \\
\text { Continue }\end{array}$ \\
\hline
\end{tabular}


Quadro 1, cont.

Table 1, cont.

\begin{tabular}{|c|c|c|}
\hline Família/Espécie & Nome Popular & Num. UFSCar \\
\hline \multicolumn{3}{|l|}{ RUTACEAE } \\
\hline Galipea jasminiflora (A.St.-Hil.) Engl. & Gramixinga & - \\
\hline Metrodorea nigra (A.St.-Hil.) & Chupa-ferro, carrapateira & - \\
\hline \multicolumn{3}{|l|}{ Pilocarpus sp. } \\
\hline Zanthoxylum chiloperone Mart. ex Engl. & Mamiqueira-fedorenta & 4508 \\
\hline Zanthoxylum riedelianum Engl. & Mamica-de-porca & \\
\hline \multicolumn{3}{|l|}{ SAPINDACEAE } \\
\hline Allophylus edulis Radlk. ex Warm. & Fruta-de-pombo & - \\
\hline Allophylus guaraniticus Radlk. & Baga-de-morcego & - \\
\hline Cupania vernalis Cambess. & Camboatá, pau-de-cantil & - \\
\hline Diatenopteryx sorbifolia Radlk. & Maria-preta & - \\
\hline Matayba elaeagnoides Radlk. & Caqui-do-mato & - \\
\hline \multicolumn{3}{|l|}{ SAPOTACEAE } \\
\hline Chrysophyllum gonocarpum Engl. & Guatambu-de-leite & - \\
\hline \multicolumn{3}{|l|}{ SOLANACEAE } \\
\hline Cestrum laevigatum Schltdl. & Coerana-branca & - \\
\hline Solanum fastigiatum Willd. & Jurubeba & - \\
\hline Solanum granuloso-leprosum Dunal & Capoeira-branca & - \\
\hline $\begin{array}{l}\text { Solanum paniculatum } \mathrm{L} \text {. } \\
\text { Solata }\end{array}$ & Jurubeba-verdadeira & 4490 \\
\hline Solanum praealtum Sendtn. & & - \\
\hline Solanum gemellum Mart. ex Sendtn. & Joá-velame & - \\
\hline \multicolumn{3}{|l|}{ ULMACEAE } \\
\hline Celtis iguanea (Jacq.) Sarg. & Grão-de-galo & - \\
\hline Trema micrantha (L.) Blume & Crindiúva & - \\
\hline \multicolumn{3}{|l|}{ URTICACEAE } \\
\hline Urera baccifera (L.) Gaudich. & Urtigão-vermelho & - \\
\hline Urera sp. & Urtigão-branco & - \\
\hline \multicolumn{3}{|l|}{ VERBENACEAE } \\
\hline Aegiphila lhotskiana Cham. & Tamanqueira & 4975 \\
\hline \multicolumn{3}{|l|}{ Lantana brasiliensis Link } \\
\hline \multicolumn{3}{|l|}{ VIOLACEAE } \\
\hline Hybanthus atropurpureus (A.St.-Hil.) Taub. & Ganha-saia & - \\
\hline Nove plantas não identificadas. & & \\
\hline
\end{tabular}

A comparação florística, pelo índice de similaridade de Sörensen, encontra-se no Quadro 2.

As espécies Astronium graveolens, Annona cacans, Rollinia silvatica, Aspidosperma ramiflorum, Vernonia diffusa, Ceiba speciosa, Protium heptaphyllum, Holocalyx balansae, Jacaratia spinosa, Croton floribundus, Centrolobium tomentosum, Machaerium stipitatum, Casearia sylvestris, Endlicheria paniculata, Cariniana estrellensis, Cedrela fissilis, Trichilia catigua,
Inga marginata, Piptadenia gonoacantha, Guapira opposita, Piper amalago, Esenbeckia febrifuga, Metrodorea nigra, Cupania vernalis, Chrysophyllum gonocarpum e Urera baccifera ocorreram em quase todas as áreas, mas somente A. graveolens, C. floribundus, M. stipitatum, C. estrellensis e C. gonocarpum foram comuns a todos os levantamentos.

Os valores encontrados para o índice de similaridade de Sörensen foram baixos, o que representa baixa

R. Árvore, Viçosa-MG, v.27, n.5, p.647-656, 2003 
similaridade florística entre as áreas. Segundo Salis (1990), as matas residuais do interior do Estado apresentam composição e estrutura bem diferentes. Porém, segundo Matteucci \& Colma (1982), valores acima de $25 \%$ indicam similaridade entre os elementos comparados por este índice, o que leva a supor uma certa uniformidade em relação à florística das matas estacionais semidecíduas do interior de São Paulo. Portanto, entre outros fatores, podem ser considerados os efeitos da fragmentação,

Quadro 2 - Similaridade florística, pelo índice de Sörensen, entre a floresta deste trabalho e de outras florestas estacionais semidecíduas do interior de São Paulo

Table 2 - Floristic similarity, by the Sörensen Index, with other mesophyllous semideciduous forest fragments in São Paulo, Brazil

\begin{tabular}{|c|c|c|c|}
\hline Local & $\begin{array}{l}\text { Número Total } \\
\text { de Espécies }\end{array}$ & $\begin{array}{l}\text { Número de } \\
\text { Espécies } \\
\text { Comuns }\end{array}$ & $\begin{array}{c}\text { Índice de } \\
\text { Sörensen (\%) }\end{array}$ \\
\hline Rio Claro ${ }^{1 /}$ & 173 & 69 & 44,95 \\
\hline Rio Claro ${ }^{2 /}$ & 189 & 67 & 41,49 \\
\hline Vaçununga $\mathrm{a}^{3 /}$ & 92 & 32 & 25,91 \\
\hline Jundiai $^{4 \prime}$ & 121 & 39 & 30,59 \\
\hline Itirapina $^{5^{5}}$ & 74 & 30 & 28,85 \\
\hline Bauru $^{6 /}$ & 56 & 25 & 26,32 \\
\hline
\end{tabular}

1/ Pagano et al. (1995), ${ }^{2 /}$ Pagano \& Leitão Filho (1987), ${ }^{3 /}$ Martins (1979), ${ }^{4 /}$ Rodrigues et al. (1989), ${ }^{5 /}$ Kotchetkoff-Henriques \& Joly (1994) e ${ }^{6 /}$ Cavassan et al. (1984). que isolam populações e dificultam a reprodução principalmente das espécies consideradas raras e, conseqüentemente, a eliminação de algumas espécies de determinados fragmentos. Há ainda de se considerar a metodologia utilizada para os levantamentos e as espécies não-identificadas neste trabalho, como também pelos outros autores, que podem alterar os valores de similaridade entre os fragmentos estudados, já que foram consideradas espécies distintas.

O índice de diversidade de Shannon-Wiener obtido neste estudo foi de 3,45nats/ind., próximo aos obtidos em florestas estacionais semidecíduas no Estado de São Paulo (Quadro 3). Segundo Martins (1991), a diversidade está entre 3,16 e 3,63 nats/ind. para as florestas do interior paulista. Para Leitão Filho (1987), a diversidade das matas de planalto é, em geral, menor que aquela observada nas florestas Amazônica e Atlântica, devendo ser ressaltado que o índice de diversidade de ShannonWiener, em florestas de planalto no Estado de São Paulo, variou de 3,16 a 4,29 nats/ind.

\section{CONCLUSÃO}

Pelos resultados obtidos no levantamento florístico, conclui-se que o fragmento estudado apresenta diversidade semelhante à encontrada em florestas residuais do interior do estado de São Paulo por outros autores, mas apresentou baixa similaridade florística com essas áreas. Entre outros fatores que justificam estes valores está o efeito da fragmentação das florestas.

Quadro 3 - Índice de diversidade de Shannon-Wiener (H') em trabalhos realizados em florestas estacionais semidecíduas no Estado de São Paulo

Table 3 - Diversity Index of Shannon-Wiener $\left(H^{\prime}\right)$ in mesophyllous semideciduous forest fragments in the state of São Paulo, Brazil

\begin{tabular}{|c|c|c|c|}
\hline Autor & Local & Método de Amostragem & $\mathrm{H}^{\prime}$ (nats/ind) \\
\hline Martins (1979) & Santa Rita do Passa Quatro & Quadrantes & 3,63 \\
\hline Matthes (1980) & Campinas & Censo $^{1 /}$ & 3,71 \\
\hline Cavassan et al. (1984) & Bauru & Quadrantes & 3,50 \\
\hline Pagano \& Leitão Filho (1987) & Rio Claro & Quadrantes & 4,29 \\
\hline Rodrigues et al. (1989) & Jundiaí & Parcelas & 3,94 \\
\hline Kotchetkoff-Henriques \& Joly (1994) & Itirapina & $\mathrm{Censo}^{1 /}$ & 3,61 \\
\hline Gandolfi et al. (1996) & Campinas & Parcelas & $3,47^{2 !}$ \\
\hline Maestro \& Gandolfi (1996) & Piracicaba & Parcelas & 3,37 \\
\hline Silva (2001) & São Carlos & Parcelas & 3,45 \\
\hline
\end{tabular}

${ }^{1 /}$ Censo completo dos indivíduos com mais de $10 \mathrm{~cm}$ de DAP e ${ }^{2 /}$ Valor médio. 


\section{AGRADECIMENTOS}

À Embrapa Pecuária Sudeste - CPPSE, pela liberação para trabalharmos na Reserva de Floresta Estacional Semidecídua. Aos profissionais que auxiliaram na identificação das espécies, Prof. Luis Carlos Marangon (UFRPE), Profa. Neusa Taroda (UNESP - São José do Rio Preto/SP), Prof. Antônio Furlan (UNESP Rio Claro/SP), Prof. Ricardo Ribeiro Rodrigues (ESALQ - Piracicaba/SP) e Marie Sugiyama (IB. SMA. SP - São Paulo/SP).

\section{REFERÊNCIAS BIBLIOGRÁFICAS}

BROWER, J. E.; ZAR, J. H. Field and laboratory methods for general ecology. Dubuque: WmC Publishers, 1984. $226 \mathrm{p}$.

CALDERANO FILHO, B. et al. Os solos da Fazenda Canchim, Centro de Pesquisa de Pecuária do Sudeste, São Carlos, SP: Levantamento semidetalhado, propriedades e potenciais. Rio de Janeiro: EMBRAPA-CNPS/São Carlos: EMBRAPA - CPPSE, 95 p. (EMBRAPA - CNPS. Boletim de Pesquisa, 7) (EMBRAPA - CPPSE. Boletim de Pesquisa, 2).

CATHARINO, E. L. M. Florística de matas ciliares. In: SIMPÓSIO SOBRE MATA CILIAR. Campinas: Fundação Cargill, 1989. p. 61-70.

CAVASSAN, O.; CESAR, O.; MARTINS, F. R.

Fitossociologia da vegetação arbórea da Reserva Estadual de Bauru, Estado de São Paulo. Revista Brasileira de Botânica, v. 7, n. 2, p. 91-106, 1984.

CESAR, O. Composição florística, fitossociologia e ciclagem de nutrientes em mata mesófila semidecídua (Fazenda Barreiro Rico, Município de Anhembi, SP). 1988. Tese - Universidade Estadual de Campinas, Rio Claro, 1988.

CONSELHO ESTADUAL DO MEIO AMBIENTE CONSEMA. Áreas naturais do Estado de São Paulo. São Paulo, 1985.

GANDOLFI, S.; LEITÃO FILHO, H. F.; JOLY, C. A. Análise florística e fitossociológica de 3 trechos distintos de uma floresta estacional semidecidual no município de Campinas, SP. In: CONGRESSO DA SOCIEDADE BOTÂNICA DE SÃO PAULO, 11., 1996, São Carlos. Anais... São Carlos: Universidade Federla de São Carlos, 1996. p. 92.
HORA, R. C. Composição florística e aspectos da estrutura da comunidade de lianas em uma mata mesófila semidecídua na Fazenda Canchim, São Carlos - SP. 1999. Dissertação (Mestrado) - Universidade Federal de São Carlos, São Carlos, 1999.

INSTITUTO BRASILEIRO DE GEOGRAFIA E ESTATÍSTICA - IBGE. 1993. Classificação da vegetação brasileira, adaptada a um sistema universal. Rio de Janeiro: 1993.

KOTCHETKOFF-HENRIQUES, O.; JOLY, C. A. Estudo florístico e fitossociológico em uma mata mesófila semidecídua da serra do Itaqueri, Itirapina, Estado de São Paulo, Brasil. Revista Brasileira de Biologia, v. 54, n. 3, p. $477-487$.

KRONKA , F. J. N. et al. Áreas de domínio do cerrado no estado de São Paulo. São Paulo: Secretaria do Meio Ambiente. 1998. 84 p.

LEITÃO FILHO, H. F. Considerações sobre a florística de florestas tropicais e sub-tropicais do Brasil. IPEF, v. 35, p. 41-46, 1987.

LORENZI, H. Árvores brasileiras: manual de identificação e cultivo de plantas arbóreas nativas do Brasil. Nova Odessa: Plantarum, 1992. v. 1. 532 p.

LORENZI, H. Árvores brasileiras: manual de identificação e cultivo de plantas arbóreas nativas do Brasil. Nova Odessa: Plantarum, 1998, v. 2. 373 p.

MAESTRO, A. L.; GANDOLFI, S. Levantamento florístico e fitossociológico de um trecho de floresta estacional semidecidual às margens do ribeirão Piracicamirim, Piracicaba, SP. In: CONGRESSO DA SOCIEDADE BOTÂNICA DE SÃO PAULO, 11., 1996, São Carlos. Anais... São Carlos: UFSCar. p. 87.

MARTINS, F. R. O método dos quadrantes e a fitossociologia de uma floresta residual do interior do Estado de São Paulo. 1979. 239 f. Tese (Doutorado) Universidade Estadual de São Paulo, São Paulo, 1979.

MARTINS, F. R. Estrutura de uma floresta mesófila. Campinas: Universidade Federal de Campinas, 1991.

MARTIUS, C. F. P.; EICHLER, A. G.; URBAN, I. Flora Brasiliensis. New York: 1967.

MATTEUCCI, S. D.; COLMA, A. Metodología para el estudio de la vegetatión. Washington, D.C.: OEA, 1982.

R. Árvore, Viçosa-MG, v.27, n.5, p.647-656, 2003 
MATTHES, L. A. F. Composição florística, estrutura e fenologia de uma floresta residual do planalto paulista: Bosque dos Jequitibás (Campinas, SP). 1980. Dissertação (Mestrado) - Universidade Federal de Campinas, Campinas, 1980.

MUELLER-DOMBOIS, D.; ELLENBERG, H. Aims and methods of vegetation ecology. New York: John Wiley \& Sons, 1974 . 547 p.

OLIVEIRA, J. B.; PRADO, H. Levantamento pedológico semidetalhado do Estado de São Paulo: quadrícula de São Carlos. Memorial descritivo. Campinas: Instituto Agronômico de Campinas. 118 p. (Boletim Técnico, 98).

PAGANO, S. N.; LEITÃO FILHO, H. F. Composição florística do estrato arbóreo de mata mesófila semidecídua, no município de Rio Claro (Estado de São Paulo). Revista Brasileira de Botânica, v. 10, p. 37-47, 1987.

PAGANO, S. N.; LEITÃO FILHO, H. F.; CAVASSAN, O. Variação temporal da composição florística e estrutura fitossociológica de uma floresta mesófila semidecídua - Rio Claro - Estado de São Paulo. Revista Brasileira de Botânica, v. 55, n. 2, p. 241-258, 1995.
RODRIGUES, R. R. et al. Estudo florístico e fitossociológico em um gradiente altitudinal de mata estacional mesófila semidecídua, na Serra do Japi, Jundiaí, SP. Revista Brasileira de Botânica, v. 12, p. 71-84, 1989.

SALIS, S. M. Composição florística e estrutura fitossociológica de um remanescente de mata ciliar do Rio Jacaré-Pepira, Brotas, SP. 1990. Dissertação (Mestrado) - Universidade Federal de Campinas, Campinas, 1990.

SILVA, L. A. Levantamento florístico e estrutura fitossociológica do estrato arbóreo de um fragmento de floresta estacional semidecidual no município de São Carlos - SP. 2001. Tese (Doutorado) - Universidade de São Carlos, São Carlos, 2001.

TABANEZ, A. J.; VIANA, V. M.; DIAS, A. S.

Conseqüências da fragmentação e do efeito de borda sobre a estrutura, diversidade e sustentabilidade de um fragmento de floresta de planalto de Piracicaba, SP. Revista Brasileira de Biologia, v. 57, n. 1, p. 47-60.

TOLENTINO, M. Estudo crítico sobre o clima da região de São Carlos. São Carlos: 1967. 